\title{
Environmental and human health issues related to pesticides: from usage and environmental fate to impact
}

\author{
Hélène Budzinski ${ }^{1}$ - Michel Couderchet ${ }^{2}$ (D) \\ Received: 21 February 2018 / Accepted: 13 March 2018 / Published online: 22 March 2018 \\ (C) Springer-Verlag GmbH Germany, part of Springer Nature 2018
}

This special issue of Environmental Science and Pollution Research highlights selected papers presented at the 46th congress of the French Group of Pesticide research (Groupe Français des Pesticides, GFP) that took place between the 15 and 17, May, 2016, in Bordeaux, France.

GFP is a scientific society that was founded in 1977 by a group of scientists from several French academic institutions (Universities, INRA, CNRS...) to establish and maintain a broad consensus between research laboratories and promote any training or information on all scientific and technical aspects of pesticides (Chollet et al. 2014).

Whether they are used as plant protection compounds or biocides, pesticides have disseminated into all environments and have yielded to a general pollution especially of the aquatic environment. Therefore, the objective of the 46th edition of the GFP congress was to gather information collected by the French scientific community and to have a critical discussion in agreement with the national "Ecophyto 2" program launched in 2015.

During the 3 days of the congress, a total of 99 presentations (48 oral and 51 poster presentations) were grouped into five sections:

Responsible editor: Philippe Garrigues

Michel Couderchet

michel.couderchet@univ-reims.fr

Hélène Budzinski

helene.budzinski@u-bordeaux.fr

1 Environnements et Paléoenvironnements Océaniques et Continentaux EPOC - UMR 5805 CNRS, Laboratoire de Physico- et Toxico-Chimie de l'environnement (LPTC), Université de Bordeaux, 351 crs de la Libération, F-33405 Talence, France

2 Unité de recherche Vignes et Vin de Champagne, Université de Reims Champagne-Ardenne, EA 4707, BP 1039, F-51687 Reims Cedex 2, France
- Diagnosis and environmental fate of pesticides: new analytical techniques, the use of chemical integrative samplers and other sampling techniques, results of pesticide survey in water, air, and soil as well as in aquatic fauna, sorption and biodisponibility, degradation...

- Impact and risks: ecotoxicological approaches, endocrine disruptors, influence of pesticide cocktails, effects of pesticides on microorganism communities and on bees, transfer between environmental compartments and from the vineyard to the wine, monitoring of spray drift...

- Human health: contamination of human population, assessment of health risk and precision agriculture, new insights into the regulation of the mode of action of neonicotinoids...

- Alternative methods and agroecology: reduction of doses through vectorization of pesticide molecules, microinjection of pesticides into trees, dimensioning of buffer strips, agroecology and alternatives in the production of Bordeaux wines...

- Social and economic aspects of pesticide use: perception of pesticide contamination by urban populations, pesticides and psychology, sociocultural resistance to changes in pesticide use in vineyards...

Of these 99 presentations, 7 were selected to appear in this special issue, while 42 of them were published in the proceedings of the congress (Budzinski et al. 2017).

Generally, non-point source pesticide contamination is attributed to intensive agriculture as it is the major user of plant protection chemicals. During 3 years, Guibal et al. (2018) monitored pesticides at six points on two watersheds and they show that extensive agriculture may also contribute to pesticide pollution on small watersheds. They show that both sampling strategies, polar organic chemical integrative samplers (POCIS) or grab sampling, provide specific information. Grab sampling for rain events and passive sampling with POCIS are complementary to measure the background level and to identify all pesticides that may be exported from a small watershed. Although the two watersheds are comparable in land 
use, detection frequency and concentrations were higher in the Aixette watershed and the presence of orchards did not seem to result in higher contamination. The most frequently recovered pesticides were banned herbicides (diuron, atrazine, simazine, norflurazon...) and/or their metabolites. Corn and cereal herbicides were also found and in most sampling points $(5 / 6)$; imidacloprid was detected with a frequency of up to $100 \%$ over the 2 years of the study.

Chlordecone contamination in the French West Indies has been discussed at several occasions in various GFP congresses, especially in 2014 when the congress was held in Martinique (Devault et al. 2016). Although this insecticide is poorly soluble in water it is transported towards marine ecosystems. Studying chlordecone content in several trophic groups from phytoplankton and macroalgae to carnivorous and piscivorous fishes, Dromard et al. (2018) were able to show a gradient in contamination from the coastal mangrove to coral reefs $3 \mathrm{~km}$ away from the coast. The highest concentrations of above $500 \mu \mathrm{g} \mathrm{kg}^{-1}$ were observed in some carnivorous fishes of the mangrove but biomagnification remains to be demonstrated.

Despite the fact that Lebanon signed the Stockholm agreement on POPs in 2001, many of the organochlorine insecticides are present at high concentration in wells of the Akkar region of the country (Chbib et al. 2018). In the 15 wells studied, the sum of concentration of organochlorine insecticides comprised between 2.61 and $58.87 \mu \mathrm{g} \mathrm{L}{ }^{-1}$. The direct use of groundwater as drinking water may present public health problems. The isomer ratios for DDTs and HCH suggest that these compounds are still being used and there is an urgent need of farmer training and education.

Classified as a persistent pollutant, chlordecone was found to be degraded at a very slow rate yielding several dechlorinated compounds, the major metabolites being mono- or tridechlorinated. Using Ames' technique and the micronucleus method, Legeay et al. (2018) were able to show that the monoor tri-dechlorinated chlordecone are devoid of genotoxicity and mutagenic activity as it is the case for the parent compound. The two metabolites had lower proangiogenic properties than chlordecone indicating that the in situ chemical reduction technique might be part of the solution to manage soil contamination in the French West Indies.

Adsorption of pesticides reduces their transfer to surface water and natural or constructed wetlands adsorbing pesticides may be used as mitigation techniques. However, adsorption in these wetlands may depend on hydraulic parameters as demonstrated by Gaullier et al. (2018). Using various water to soil ratios and agitation protocols, they were able to show that pesticides adsorbed best when less water was present and that agitation favored adsorption especially for the more hydrophobic compounds. The equilibrium was also faster achieved for higher water to soil ratios. Extrapolating their results, it seems that evaluating the efficiency of constructed wetlands should consider hydrodynamics parameter and the seasonality of water flow.
An elegant way of reducing the applied dose of pesticide would be to improve the amount that is taken up by plants and turn a contact compound into a systemic one. This is described in Wu et al. (2018). Using click chemistry, they conjugated glucose or glutamic acid to the contact fungicide fenpiclonil and show that the fungicide derivatives were transported in the phloem of castor bean plants. Conjugating the amino acid was more favorable. Studying deeper into the mechanism, they prove that this phloem transport of the amino acid conjugate was stereo-specific and depended on an energy-dependent amino acid carrier system. Releasing the active fungicide inside the plant would enable the control of endophytic fungi and offer a solution to diseases such as grape trunk disease. This research is yet to come.

The last paper of the special issue addresses pesticide linked human health problems (Harmouche-Karaki et al. 2018). The level of four organochlorine pesticides was monitored in a Lebanese population and associations were tested with several characteristics of the population. No difference was found between men and women contamination, no association could be found with domestic use of the pesticides, or body mass index, or food consumption except for milk and $\beta$ HCH. Smokers' serum contained less pesticide. It appears that the concentration in this population from the Beirut area was lower than that reported for several countries worldwide excluding any health risk due to the four monitored pesticides. A similar study in populations from another Lebanese region (Akkar) where the wells are highly contaminated (Chbib et al. 2018) might show different results.

The seven articles of this special issue deal with diagnosis, environmental impact, alternatives, and health issues linked to pesticides. They only reflect in part the diversity of the presentations and discussions of the GFP-2016 congress and the readers are invited to find more details in the proceedings (Budzinski et al. 2017) and our website www.gfpesticides. org. We will also be pleased to interact with the readers every year at our future congresses.

Acknowledgements We would like to thank our partners for this congress: EPOC, CNRS, Université de Bordeaux, Bassin d'Arcachon, Agilent Technologies, Serlabo Technologies, RIC, LabEx COTE, Thermo Fisher, F-DGSi, CIL, and CASDEN.

\section{References}

Budzinski H., Chollet J.-F., Couderchet M., Devault D. (2017) Enjeux environnementaux et sanitaires associés aux pesticides: de leur usage à leur dispersion dans l'environnement en lien avec leur impact. Les Editions du GFP, ISBN 978-2-9545611-7-2, 199 p.

Chbib C, Net S, Hamzeh M, Dumoulin D, Ouddane B, Baroudi M (2018) Assessment of pesticide contamination in Akkar groundwater, northern Lebanon. Environ Sci Pollut Res in press

Chollet JF, Couderchet M, Bonnemain JL (2014) 42nd congress of the "Groupe Français ds Pesticides" (French Group of Pesticide research - GFP 2012). Environ Sci Pollut Res 21:4974-4976 
Devault DA, Macarie H, Lemoine S (2016) Crop protection and environmental health: legacy management and new concepts. Environ Sci Pollut Res 23:1-2

Dromard CR, Guéné M, Bouchon-Navaro Y, Lemoine S, Cordonnier S, Bouchon C (2018) Contamination of marine fauna by chlordecone in Guadeloupe: evidence of a seaward decreasing gradient.

Gaullier C, Dousset S, Billet D, Baran N (2018) Is pesticide sorption by constructed wetland sediments governed by water level and water dynamics? Environ Sci Pollut Res in press.

Guibal R, Lissalde S, Leblanc J, Cleries K, Charriau A, Poulier G, Mazzella N, Rebillard JP, Brizard Y, Guibaud G. (2018) Two sampling strategies for an overview of pesticide contamination in an agriculture-extensive headwater stream. Environ Sci Pollut Res in press.

Harmouche-Karaki M, Matta J, Helou K, Mahfouz Y, Fakhoury-Sayegh N, Narbonne JF (2018) Serum concentrations of selected organochlorine pesticides in a Lebanese population and their associations to sociodemographic, anthropometric and dietary factors: ENASB study. Environ Sci Pollut Res in press

Legeay S, Billat PA, Clere N, Nesslany F, Bristeau S, Faure S, Mouvet C (2018) Two dechlorinated chlordecone derivatives formed by in situ chemical reduction are devoid of genotoxicity and mutagenicity and have lower proangiogenic properties compared to the parent compound.

Wu H, Marhadour S, Lei ZW, Yang W, Marivingt-Mounir C, Bonnemain JL, Chollet JF (2018) Vectorization of agrochemicals: amino acid carriers are more efficient than sugar carriers to translocate phenylpyrrole conjugates in the Ricinus system. Environ Sci Pollut Res in press

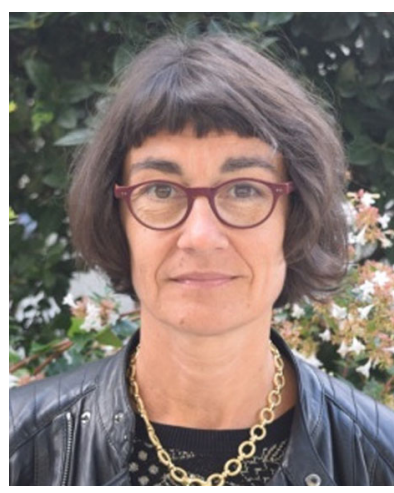

Hélène Budzinski is a CNRS research director and in charge of the LPTC (Laboratory of Physico- and Toxico-Chemistry of the Environment) which is a research group of EPOC (UMR 5805 University of Bordeaux/ CNRS). She is co-director of LabEx COTE. She is an environmental chemist. Her research focuses on various classes of organic contaminants (PAHs, PCBs, pesticides, pharmaceutical substances, endocrine disruptors, detergents...) studying presence, fate, and toxic impacts. Her research activity is dedicated on one hand to the development of analytical tools for the determination of chemical pollutants at ultra-trace levels (extraction, purification, quantification, identification methodologies) with an emphasis these last years on passive samplers. On the other hand, she is involved in the study of biotic and abiotic phenomena affecting the presence of organic contaminants in the environment and their transfer towards organisms. She is the author of more than 250 publications and of 68 invited conferences, and she was awarded several prizes: the brass medal of the CNRS (1995), the silver medal of the CNRS (2017), the French Chemistry Society (SFC) prize for the analytical chemistry division (1997), and the ADEME prize for environment innovative techniques $(1998,2002,2010)$; she is Knight of the National Order of the Merit (2009) and Knight of the Legion of Honour (2015). She has been since 2008 a member of several scientific councils such as those of ONEMA, IRD, Chronic Risk Division of the INERIS, Planet and Universe CNRS Institute.

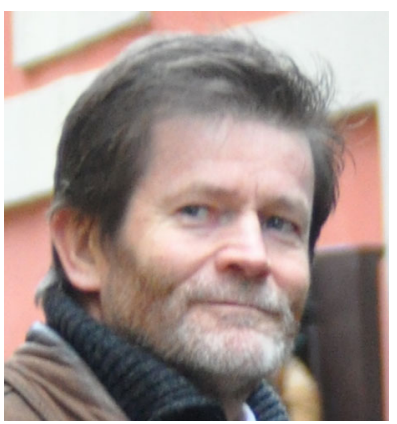

Michel Couderchet is Professor in the Unité de Recherche Vigne et Vin de Champagne at the University of Reims, France. He received his Master's degree from the University of Minnesota (USA) and his $\mathrm{PhD}$ in plant biology in 1988 from the University of Besançon (France). After 2 years at the BASF Agronomy Research Station in Limburgerhof (Germany), he was appointed in 1989 as assistant professor at the University of Constance (Germany) and at the University of Reims in 1995. He became full professor in 2003. His main interests include the effects of pesticides on the physiology of target and nontarget plants, the behavior, fate, and bioavailability of pesticide in the environment, ecotoxicology of pesticides, and soil and water pollution by these compounds. He has co-authored over 60 peer-reviewed papers in these domains and participated in over 100 poster or oral presentations in conferences around the world. He is president of the GFP. 